vam analisar o conhecimento e utilização que estudantes faziam não só das ferramentas colaborativas da Google mas também das redes sociais e da web. Para tal, foi efetuada a análise descritiva dessa utilização mediante percentagens e frequências. Procedeu-se a uma análise fatorial exploratória que permitiu, entre outras competências transversais, identificar o domínio 'conhecimento do projeto e suas ferramentas'. O efeito da participação no projeto foi avaliado comparando as pontuações atribuídas às questões nos $1 .^{\circ}$ e $2 .^{\circ}$ questionários através do Teste de Mann-Whitney. Foi considerado um nível de significância de 5\%. Resultados: Não existiram diferenças estatisticamente significativas entre os estudantes que responderam aos dois questionários. No que concerne à utilização e conhecimento prévio das ferramentas colaborativas, as mais referidas foram o Gmail (96.4\%) e o Drive (82.1\%). 4.8\% haviam utilizado a Classroom (4.8\%) e $2.4 \%$ a Sites. Quanto à utilização de redes sociais e da web como meio de comunicação, $90 \%$ responderam 'frequentemente" ou "sempre" a ambas as questões. Quanto à evolução ao longo do projeto, no que se refere ao domínio "conhecimento do projeto e suas ferramentas", as respostas apresentadas permitem aferir uma melhoria estatisticamente significativa com um valor de $p<0.001$. Conclusões: O projeto revelou-se positivo no que toca à aquisição de competências na utilização das ferramentas colaborativas da Google.

http://doi.org/10.24873/j.rpemd.2019.12.636

\#179 Análise da aquisição de competências técnicas e pessoais numa experiência pedagógica CrossMark

Maria João Ponces, Saúl Castro, Marta Jorge*, Berta Meireles, Carlos Pires, Eugénio Martins

Universidade de Trás-os-Montes e Alto Douro, Faculdade de Medicina Dentária da Universidade do Porto

Objetivos: Este estudo exploratório apresenta os resultados preliminares recolhidos a partir de dois questionários relacionados com uma experiência pedagógica realizada em grupos na unidade curricular de Tecnologias de Informação e Comunicação da Faculdade de Medicina Dentária da Universidade do Porto, cujo intuito principal foi promover as denominadas soft e hard skills. Num projeto conjunto visando apoiar uma Instituição de Solidariedade Social e com o recurso às ferramentas colaborativas da Google, os estudantes construíram um website ligado às páginas do Facebook, do Twitter e Instagram bem como uma newsletter. O objetivo do presente estudo foi perceber o impacto que o projeto apresentou como resultados de aprendizagem, na aquisição de competências pessoais e técnicas. Materiais e métodos: Os dados foram recolhidos a partir de dois questionários elaborados para o efeito e respondidos por 84 estudantes antes do início e 57 no final do projeto. Mediante o teste do Qui-quadrado, averiguou-se a consistência na amostra que respondeu a ambos os questionários. Estes visavam analisar a aquisição de competências proporcionadas pelo projeto. Para tal, procedeu-se a uma análise fatorial exploratória com o objetivo de identificar os domínios avaliados pelo questionário, no que se refere a competências transversais. O efeito da participação no projeto, nos domínios obtidos na análise fatorial, foi avaliado comparando as pontuações atribuídas às questões nos $10^{\circ}$ e $2 .^{\circ}$ questionários através do Teste de Mann-Whitney. Foi considerado um nível de significância de 5\%. Resultados: Não existiram diferenças estatisticamente significativas entre os estudantes que responderam ao questionário antes e após o projeto. A análise fatorial exploratória levou à identificação de 5 domínios: 'comunicação", "conhecimento do projeto e suas ferramentas" (hard skills), "trabalho em grupo/integração", "autonomia" e "preocupações sociais" (soft skills). Quanto à evolução ao longo do projeto, as respostas apresentadas permitiram aferir uma melhoria estatisticamente significativa, com um valor de $\mathrm{p}<0.05$, nos domínios "conhecimento do projeto e suas ferramentas" e "trabalho em grupo/integração". Conclusões: O projeto colaborativo instituído revelou-se positivo não só no que toca à aquisição de competências técnicas na utilização das ferramentas colaborativas, mas também pessoais colaborativas e de integração.

http://doi.org/10.24873/j.rpemd.2019.12.637

\section{\#180 Efeito antibiofilm do extrato de Cranberry num modelo validado de biofilm in vitro}

David Simões Martins*, María del Carmen Sánchez, Honorato Ribeiro-Vidal, Begoña Bartolomé, Mariano Sanz, David Herrera

Instituto de Investigación en Ciencias de la Alimentación, Grupo de investigação ETEP, Facultad de Odontología, Universidad Complutense de Madrid

Objetivos: Avaliar a capacidade antibiofilm do extrato de Cranberry frente aos patógenos periodontais Porphyromonas gingivalis, Aggregactibacter actinomycetemcomitans e Fusobacterium nucleatum, num modelo validado de biofilm in vitro. Materiais e métodos: Para avaliar o efeito do extrato de Cranberry $(200 \mu \mathrm{g} / \mathrm{mL})$ na incorporação bacteriana num biofilm in vitro, prepararam-se preinóculos mistos com seis espécies bacterianas representativas dos colonizadores iniciais (Streptococcus oralis e Actinomyces naeslundii), precoces (Veillonella parvula), secundários (F. nucleatum) e tardios (P. gingivalis e A. actinomycetemcomitans), a nível subgengival. Os preinóculos foram colocados em contacto com o extrato e um disco de hidroxiapatite, numa placa de cultivo celular, durante 6 horas, para estudar a formação e evolução precoces do biofilm. Utilizou-se solução salina tamponada com fosfato e dimetil sulfóxido $4 \%$ como controlos. O efeito do extrato na carga bacteriana ([unidades formadoras de colónias viáveis por mililitro (UFC/mL)], nas primeiras horas de desenvolvimento do biofilm in vitro, foi estudado pela técnica da reação em cadeia da polimerase quantitativa $(n=9)$. A proporção (\%) de células vivas/mortas no biofilm tratado foi analisada por microscopia confocal $(n=3)$. Usou-se o teste Shapiro-Wilk para avaliar normalidade da amostra e o teste ANOVA para estudar efeito de cada solução nas variáveis UFC/mL e \% de células vivas/mortas. Os resultados foram considerados estatisticamente significativos em $\mathrm{p}<0,05$. Resultados: A incorporação das seis espécies bacterianas no biofilm foi reduzida significativamente pela ação do extrato de Cranberry, nas seis pri- 
meiras horas de desenvolvimento do modelo de biofilm in vitro. Observaram-se reduções significativas na contagem dos patógenos periodontais P. gingivalis $(97,3 \%)$, A. actinomycetemcomitans $(84,0 \%)$ e F. nucleatum $(75,7 \%)$ nos biofilms tratados com o extrato, sem afetar a viabilidade bacteriana $(\mathrm{p}<0,001)$. Em relação a P. gingivalis, o patógeno periodontal cuja adesão bacteriana foi mais afetada pelo extrato, obteve-se

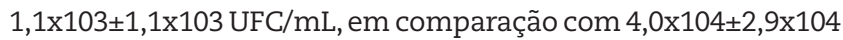
$\mathrm{UFC} / \mathrm{mL}$, nos biofilms controlo $(\mathrm{p}<0.001)$. Conclusões: $\mathrm{O}$ extrato de Cranberry reduziu significativamente a adesão bacteriana dos patógenos periodontais P. gingivalis, A. actinomycetemcomitans e F. nucleatum, nas seis primeiras horas de desenvolvimento do biofilm in vitro, sem afetar a viabilidade bacteriana. Desta forma, este extrato poderá ser benéfico como coadjuvante no tratamento das doenças periodontais. http://doi.org/10.24873/j.rpemd.2019.12.638

\section{\#181 Efeito de preparações ultrassónicas na adesão dentinária utilizando diferentes estratégias}

Elsa Reis Carneiro*, Rui Isidro Falacho, Leandro Martins, Francisco Caramelo, Fernando Guerra

Faculdade de Medicina da Universidade de Coimbra, Faculdade de Odontologia da Universidade Federal do Amazonas

Objetivos: Avaliar e comparar duas técnicas distintas de preparação dentária (pontas ultrassónicas diamantadas vs brocas diamantadas convencionais), quanto à adesão dentinária obtida com duas estratégias adesivas distintas (autocondicionamento vs condicionamento total), por meio de um teste de resistência adesiva por microtração ( $\mu \mathrm{TBS})$. Materiais e métodos: Um total de 16 molares permanentes intactos foram recolhidos, divididos em metades com um disco de diamante e distribuídos em quatro grupos de acordo com o método de preparação e o sistema adesivo utilizado. Uma das metades foi preparada com recurso a ponta ultrassónica diamantada e a outra com uma broca diamantada. Após este procedimento, cada área foi restaurada com resina composta até ser obtido um cilindro de $6 \mathrm{~mm}$ de altura sobre a superfície exposta. Em seguida, os dentes foram seccionados para obtenção de bastonetes uniformes que foram então submetidos ao teste de microtração ( $\mu \mathrm{TBS})$, utilizando uma máquina de testes universal. A análise estatística dos valores obtidos foi realizada pelos testes Shapiro-Wilk e Leven. A influência de ambas as variáveis foi analisada utilizando Two-way ANOVA. Resultados: Não houve diferenças estatisticamente significativas entre os valores médios de força de adesão no que toca ao sistema adesivo $(F(1,24)=1,004, p=0,326)$, nem quanto ao tipo de corte $(F(1,24)=2,505, p=0,127)$, nem no que diz respeito à interação entre os dois fatores $(F(1,24)=0,040, p=0,840)$. Conclusões: Ambas as estratégias adesivas apresentaram valores similares de $\mu$ TBS, portanto podem ser igualmente eficazes independentemente da técnica de preparação. Em relação ao método de preparação, os grupos em que foram utilizados instrumentos ultrassónicos apresentaram os maiores valores de força de adesão, independentemente da estratégia adesiva, embora sem significância estatística. É imprescindível a realização de mais estudos, com aplicação de metodologias standard, para clarificar as relações entre as variáveis testadas. http://doi.org/10.24873/j.rpemd.2019.12.639

\section{\#182 Capacidade mastigatória de indivíduos geriátricos institucionalizados}

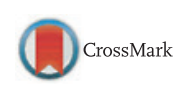

Sarah Goolamhussen*, Joana Maria Figueiredo Ferreira dos Santos, Patrícia Fonseca, Nélio Veiga

Universidade Católica Portuguesa - Instituto de Ciências da Saúde de Viseu

Objetivos: Durante vários anos, as próteses removíveis convencionais foram consideradas o tratamento de eleição para o edentulismo, porém nem sempre são satisfatórias ao nível mastigatório. Este estudo pretende caracterizar a capacidade mastigatória de idosos institucionalizados, portadores ou não de prótese dentária e clarificar a sua vantagem nesta função estomatognática. Materiais e métodos: Trata-se de um estudo observacional transversal com idosos residentes em Viseu, mais concretamente no Lar Viscondessa São Caetano e no Centro Social Paroquial Rio de Loba. Foi obtida uma amostra de 63 indivíduos (44 mulheres e 19 homens), com idades compreendidas entre os 60 e os 99 anos. Na recolha de dados foi aplicado o instrumento de estudo da capacidade mastigatória - Índice de Leake e avaliada a presença de reabilitação protética. A informação recolhida foi introduzida e analisada no software IBM SPSS Statistics ${ }^{\circledR}$ com o limiar de significância estatística de 5\%. Resultados: A maioria dos pacientes com prótese dentária $(61,9 \%)$ consegue mastigar alimentos moles sem dificuldade, como a salada (81\%) e os legumes cozidos (68,3\%). Apesar de conseguirem comer com dificuldade alimentos mais consistentes como a carne $(49,2 \%)$ tendem a evitá-los. Uma grande parte dos idosos sente dificuldade a mastigar alimentos duros e mais de metade dos não reabilitados não conseguem mastigar estes alimentos. Verifica-se uma relação estatisticamente significativa entre a presença de prótese e a capacidade mastigatória de alimentos duros $(p<0,05)$. Apesar da capacidade mastigatória dos idosos portadores de prótese ser superior aos não portadores, os alimentos mais duros tendencialmente são evitados e a alimentação adotada tende a ser idêntica em ambos os grupos. Conclusões: Dado o crescimento exponencial de indivíduos geriátricos na população portuguesa e uma vez que as suas reabilitações protéticas influenciam diretamente a sua capacidade mastigatória, é imprescindível avaliar e corrigir a qualidade das mesmas de forma a incrementar a qualidade de vida destes portadores. http://doi.org/10.24873/j.rpemd.2019.12.641 